\title{
CONTROL OF WELDING DEFORMATION IN THIN PLATE
}

\author{
Muhammad Taha Ali \\ "Dunarea de Jos" University of Galati, \\ Faculty of Naval Architecture, Galati, Domneasca \\ Street, No. 47, 800008, Romania, \\ E-mail:tahaali892@hotmail.com
}

\author{
Renardo-Florin Teodor \\ "Dunarea de Jos" University of Galati, \\ Faculty of Naval Architecture, Galati, Domneasca \\ Street, No. 47, 800008, Romania, \\ E-mail: florin.teodor@ugal.ro
}

\begin{abstract}
Welding is a process to join metals with different arrangements of the plates. In the shipbuilding industry, the joining of plates in such a way as to ensure higher productivity is very important, but the industry has been facing the problem of deformation for seven decades. The shipbuilding industry is trying to control this problem, but thin plates bring non-linear problems in the structure, especially in the bulkhead of the structure that leads to more deformation due to small members of the profiles. This problem occurs in the construction of yachts because clients need good outlook of the ship. To control this problem the computational analysis is the more productive method than other to solve this deformation problem. The thermal elastic plastic FEM method is used to analyse the thermal and mechanical problems. This analysis confirmed that this TEP - Finite Element Method is applicable for the control of deformation in the thin plate.
\end{abstract}

Keywords: Welding, Welding deformation, Analysis, TEP - FEM.

\section{INTRODUCTION}

\subsection{BACKGROUND}

The modern manufacturing industry like ship, aircraft, automobile and train requires to improve the fuel economy and carrying capacity and capability. That is why shipbuilding industries are focused on minimizing the weight of the ship to decrease the fuel consumption and increase the efficiency of the ships. For this reason thin plate structures are widely used in the ship structure.

Assembly of the metal structure, welding technique is more useful technique is employed in the shipbuilding industry and this method give significant results and advantages. But in the construction of welded structure there are some problems regarding deformation are faced by the industry, which are:
1. Decrease in work productivity of

2. Decrease in the geometrical precision

3. Increase in the shipbuilding cost

Because of these reasons the whole production time of the shipbuilding is delayed.[1]

The welding distortion is effected due to the localized heating and heat source. It is also effect the welding stresses of the metal structure. The material properties play an important role in the welding stress and welding distortion because the thermal properties of the material are important to control the welding distortion and help in the selection of the material in the structure.

For the prediction of residual stress and welding distortion several experiments were performed. The experimental methods used in the past are given below: 
1. $\mathrm{X}$ - ray diffraction

2. Stress - relaxation

3. Ultrasonic inspection

But nowadays the computational method is a more powerful tool then these methods. Because it is more cost effective then the above methods of prediction. These days the FEM method is more commonly used in welded structures to analyse the thermo mechanical behaviour. For Thermo-mechanical behaviour, the analysis is performed in the FEM is Thermal Elastic Plastic - FEM Analysis.

That is why FEM codes and simulation are using these days and it is become the popular tool for the prediction of welding distortion and welding residual stresses.

To control the deformation, lots of papers and theses were performed experimentally and numerically. But still this problem is faced by shipyards. Most of the researchers nowadays are working on the thermal and mechanical response. This is because of the highly effective predicting tool Finite element simulation give the good result of thermos mechanical behaviour.

Stepwise past research development are given below;

1. Kumose et al. [2], he develop the experimental method. By using the different welding parameters he measure the angular distortion in $\mathrm{T}$ - Joint.

2. Finch and Burdekin [3], he used the Finite Element code of ABAQUS. With the help of ABAQUS he analysis the residual stresses on the different types of $\mathrm{T}$ - fillet joints.

3. Arnold [4], he developed the Finite Element code PAFEC. This code is used to predict the residual stress of the fillet weld in the multi pass.

4. Michaleris and DeBiccari [5], both of them developed the computational model and used it to estimate the buckling and deformation on the complex $\mathrm{T}$ joint fillet weld. They also improved the angular distortion.
For this research investigation, T.L. Teng et al. investigation is consider to perform the thermal elastic-plastic analysis. This thermal elastic-plastic analysis technique is used to analyse the thermal and mechanical behaviour of the structure which help to evaluate the two parameters of the $\mathrm{T}$ - joint fillet weld:

1. Residual Stress and

2. Welding Distortion

\subsection{SCOPE OF THE CURRENT STUDY}

By using the thermal mechanical uncoupled formulation: we can analyze the thermal and mechanical Behaviour of the structure. Due to the welding procedure, the dimensions are changed. As well with the small change in the mechanical behaviour. This WPS and mechanical behaviour are used to compare the thermal energy result by the welding, this is the main reason to use uncoupled formulation. The thermo physical and Mechanical Properties are dependent on temperature. This make the formulation as a combination of two parameters which are given below:

1. Temperature Field and

2. Stress

In this paper, the thermal physical analysis and the mechanical analysis problem are solved separately. [6]

Each case study in this research paper has two phases which are:

1. Thermal Analysis Phase and

2. Mechanical Analysis Phase

\section{MODELING}

\subsection{BACKGROUND}

The model assume to be a temperature dependent. It is means that thermal analysis is used to be source of mechanical behaviour in the TEP-FEM analysis. The following mechanical properties are the dependent of temperature is given below:

1. Yield Stress 
2. Elastic Modulus

3. Thermal Expansion and

4. Poisson`s ratio.

The same heat source and the same material of the model are used for the analysis in transient thermal condition for the fillet welding. This analysis was performed by the Barsoum et al. [7]

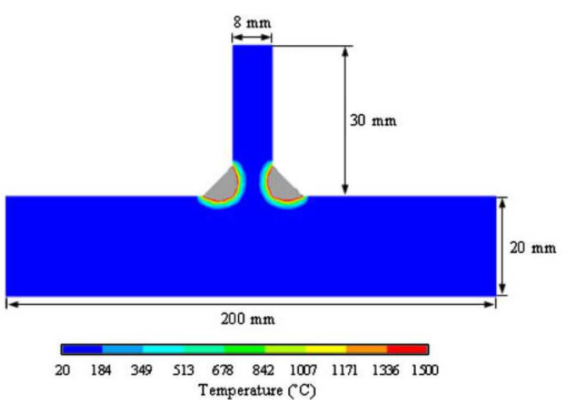

Figure 1. T-fillet welding performed to analyze thermal condition, isotherms and fusion zone at the same time. [7]

\subsection{MODEL}

The dimension of base plate is consider in these case studies are $1000 \mathrm{~mm}$ in width, $1500 \mathrm{~mm}$ in length and $5 \mathrm{~mm}$ in thickness, for the computational analysis. These dimensions is taken from the yachtbuilding pannel. The longitudinal flat bar dimensions are also taken from the yachtbuilding pannel, the dimension of the flat bar is $65 \times 5 \mathrm{~mm}^{2}$.

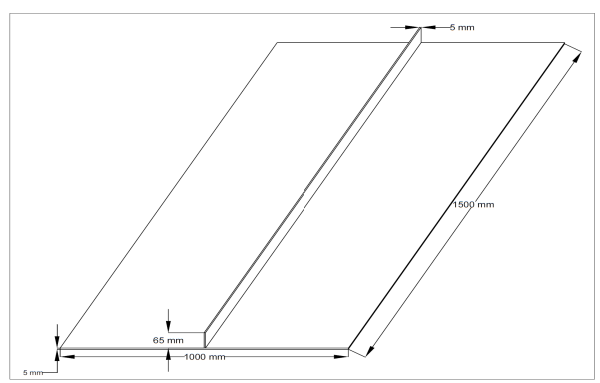

Figure 2. Model \# 1 in FEMAP, Base Plate and Longitudinal Flat Bar.
IACS Rule \# 47 is used for the computational analysis and experimental analysis. By this rule we can categorised the steel through following parameters which are define by the IACS Rule \# 47 are:

1. Yield Stress

2. Tensile Stress

3. Elongation

4. Average impact energy

By this rule we can compare the normal and high strength hull structural steel grade.

\subsection{MATERIAL SELECTION}

In the shipbuilding industry, two grades of steel are commonly used in the yacht building. The first one is Grade $\boldsymbol{A}$ and the second is Grade A36. That is why, in the research paper the first case study is material selection. Its means that for thin plate which grade of steel is useful for yacht building.

Case Study \# 1: Material selection between Grade A and Grade A36 steel.

For material selection, TEP-FEM analysis are performed to get the thermal and mechanical results which help for the selection of material for future analysis.

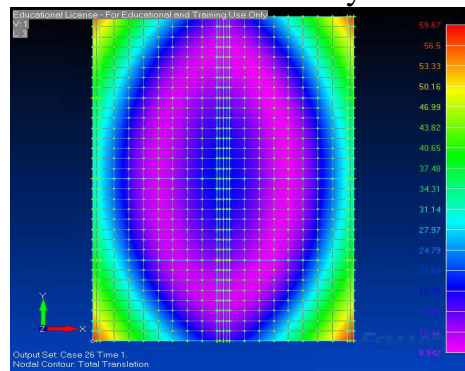

Figure 3. Deformation in Grade A Steel,

The maximum Deformation in Grade A steel is $59.67 \mathrm{~mm}$ which is near to the end of the flat bar. 


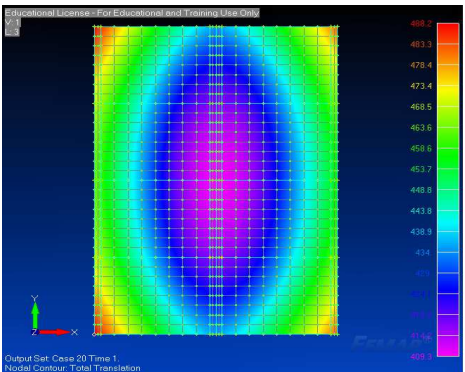

Figure 4. Deformation in Grade A36 Steel.

The maximum Deformation in Grade A36 steel is $488.2 \mathrm{~mm}$ which is near to the end of the flat bar. Form the above simulation it is clearly shows that Grade A has less plasticity then Grade A36. So for this dimension of thin plate, Grade A steel is better for further research and analysis. Grade A Steel is most commonly used steel in the shipbuilding industry. This steel is mild and hotrolled. Welding properties of this steel are excellent.

\subsection{COMPOSITION AND PROPERTIES}

Chemical composition of the Grade A steel:

\begin{tabular}{|c|c|}
\hline Element & $\begin{array}{c}\text { Max. wt./ } \\
\text { Content \% }\end{array}$ \\
\hline $\mathrm{Fe}$ & 96.72 \\
\hline $\mathrm{Mn}$ & 2.5 \\
\hline $\mathrm{C}$ & 0.21 \\
\hline $\mathrm{Si}$ & 0.5 \\
\hline $\mathrm{P}$ & 0.035 \\
\hline $\mathrm{S}$ & 0.035 \\
\hline
\end{tabular}

Table 1. The chemical composition of Grade A steel. [8]

Mechanical Properties of the Grade A steel;

\begin{tabular}{|l|l|}
\hline Mechanical Properties & \multicolumn{1}{|c|}{ Metric } \\
\hline Modulus of Elasticity & $200 \mathrm{GPa}$ \\
\hline Bulk Modulus & $140 \mathrm{GPa}$ \\
\hline Poisson's Ratio & 0.3 \\
\hline Shear Modulus & $79.3 \mathrm{GPa}$ \\
\hline Yield Stress & $235 \mathrm{MPa}$ \\
\hline Tensile Strength & $400-502 \mathrm{MPa}$ \\
\hline
\end{tabular}

Table 2. Mechanical Properties of Grade A steel. [9]
Thermal Properties of the Grade A steel;

\begin{tabular}{|l|l|}
\hline \multicolumn{1}{|c|}{ Thermal Properties } & \multicolumn{1}{c|}{ Metric } \\
\hline Thermal Expansion & $11 \times 10^{-6{ }^{\circ} \mathrm{C}^{-1}}$ \\
\hline Thermal Conductivity & $0.084 \frac{\mathrm{W}}{\operatorname{mmx} x^{\circ \mathrm{C}}}$ \\
\hline Specific Heat & $480 \frac{\mathrm{l}}{\mathrm{Kax} x^{\circ \mathrm{C}}}$ \\
\hline Initial Temperature & $20^{\circ} \mathrm{C}$ \\
\hline Final Temperature & $1500^{\circ} \mathrm{C}$ \\
\hline
\end{tabular}

Table 3. Thermal Properties of Grade $A$ steel. [9]

\section{METHOLOGY}

The methodology to analysis the both thermal and mechanical behaviour of the thin plate structure through the flow diagram below. If mechanical behaviour results are not correct then consider to start again from the Thermal Analysis of the FEM.

Thermal analysis give the result of uniform thermal distribution of temperature in the thin plate. Use the result of thermal analysis to analyse mechanical analysis in FEM. The Result of mechanical analysis give stress, strain and displacement of the structure.

Stepwise methodology of the thermal elastic plastic FEM analysis are shown below;

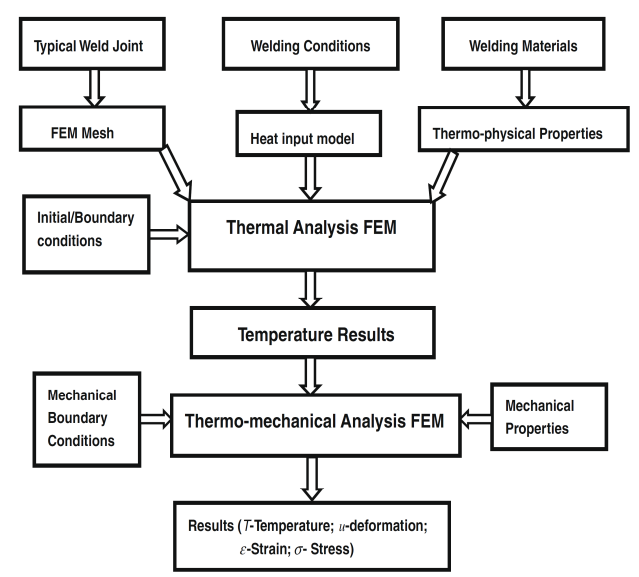

Figure 5. Research methodology flow diagram. [10] 


\section{FEMAP ANALYSIS AND RESULTS}

For the thermal and mechanical analysis, FEMAP software is used and FEMAP NASTRAN is used as a Solver. For Simple and complex calculation this software is accurate and friendly user interface software.

Model of the structure is built in FEMAP. After the simulation FEMAP have an option to formed, contours and plots.[11]

This research paper have four case studies, title of the case studies are given below:

Case Study \# 2: Fillet Joint Weld - Longitudinal member

\section{Model}

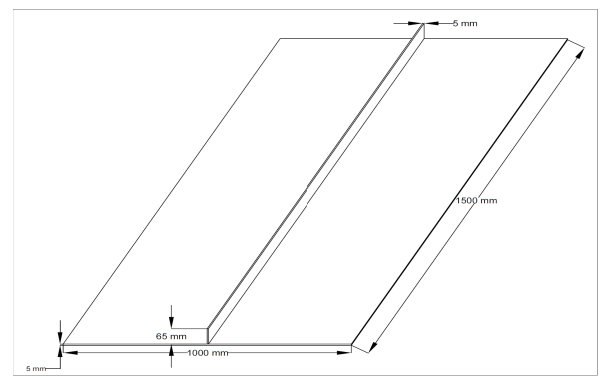

Figure 6. Model \# 1 in FEMAP, base plate and longitudinal flat bar.

\section{Condition}

In this case study, model have only one longitudinal member which weld in the centre of the base plate. Free boundary condition is consider in this case study. The number of nodes of the model are 957 and number of elements are 896.

\section{Thermal Analysis}

Uniform heat distribution is shown the figure from $1500^{\circ} \mathrm{C}$ to $20^{\circ} \mathrm{C}$. High temperature intense area are shown near to the welding bead and gradually decrease in temperature near to the edge of the plate.

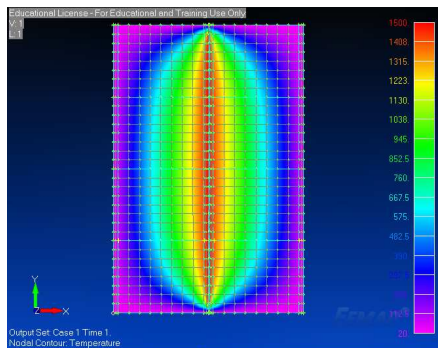

Figure 7. Thermal Analysis of the structure w.r.t. temperature.

\section{Nonlinear Plate Top VonMises Stress Analysis}

The VonMises Stress in this case study is $235 \mathrm{MPa}$. Due to residual stress in the structure cause deformation. Deformation is analysed by the displacement analysis, in the same case study.

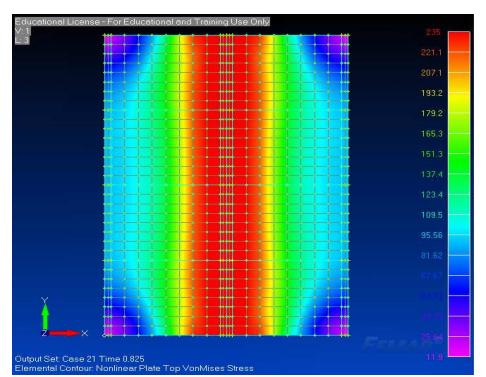

Figure 8. Nonlinear Plate Top VonMises Stress Analysis of the structure.

\section{Displacement Analysis}

Total deformation in this condition is much higher than normal condition. Its means that the structure is deformed. So possibility of distortions are increased. In this case study the total deformation is $115.5 \mathrm{~mm}$. 


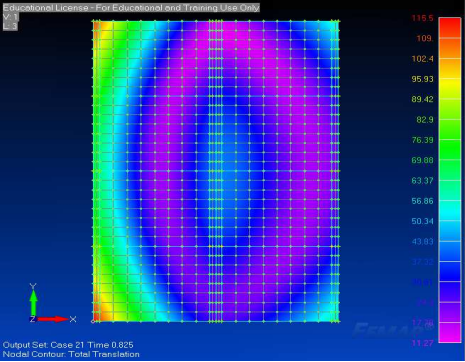

Figure 9. Deformation in the structure.

With mechanical analysis results in this case study shows that the deformation in the structure is high.

Case Study \# 3: Fillet Joint Weld - Longitudinal member with two transverse fairing members.

\section{Model}

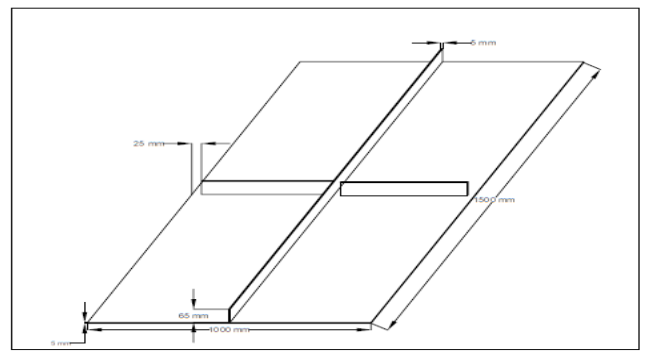

Figure 10. Model \# 2 in FEMAP, base plate and one longitudinal flat bar and two transverse flat bar.

\section{Condition}

In this case study, model has one longitudinal member with two transverse fairing member which are welded by the continuous welding with the base plate. Free boundary condition is consider in this case study. The number of nodes of the model is 1101 and number of elements is 944 .

\section{Thermal Analysis}

Uniform heat distribution is shown the figure from $1500^{\circ} \mathrm{C}$ to $20^{\circ} \mathrm{C}$. High temperature intense area are shown near to the welding bead and gradually decrease in temperature near to the edge of the plate.

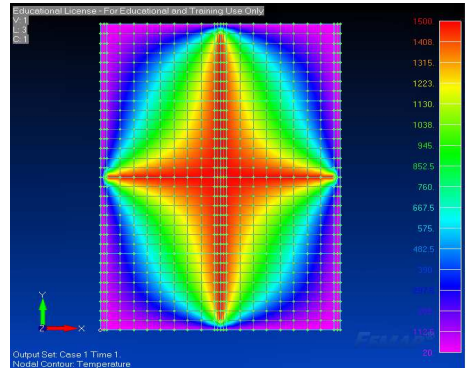

Figure 11. Thermal Analysis of the structure w.r.t. temperature.

\section{Nonlinear Plate Top VonMises Stress Analysis}

The VonMises Stress in this case study is $235 \mathrm{MPa}$. Due to residual stress in the structure cause deformation. Deformation is analysed by the displacement analysis, in the same case study. duced.

The distortion in this case study is re-

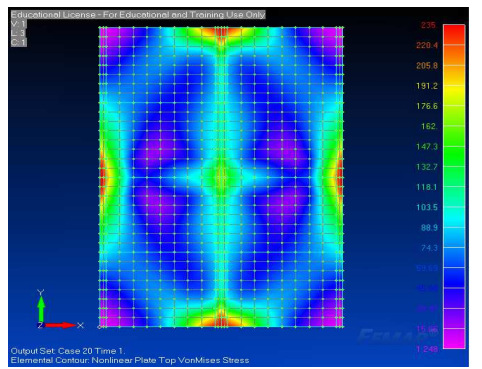

Figure 12. Nonlinear Plate Top VonMises Stress Analysis of the structure.

\section{Displacement Analysis}

Total deformation in this condition is much lower than case study \# 2. Its means that the structure is less deformed. So possibility of distortion is decreased. In this case study the total deformation is $13.96 \mathrm{~mm}$.

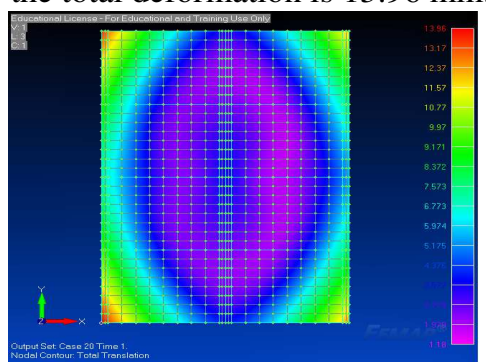


Figure 13. Deformation in the structure.

With mechanical analysis results in this case study shows that the deformation in the structure is lower than the case study \# 2 .

Case Study \# 4: Fillet Joint Weld - Longitudinal member with six transverse fairing members.

\section{Model}

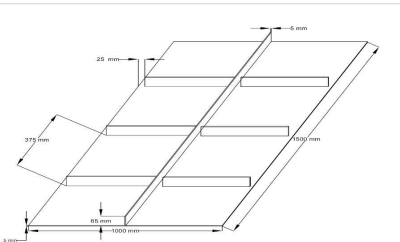

Figure 14. Model \# 3 in FEMAP, base plate, one longitudinal flat bar and six transverse flat bars.

\section{Condition}

In this case study, model has one longitudinal member with six transverse fairing member which are welded by the continuous welding with the base plate. Free boundary condition is consider in this case study. The number of nodes of the model are 1119 and number of elements are 1040.

\section{Thermal Analysis}

Uniform heat distribution is shown the figure from $1500^{\circ} \mathrm{C}$ to $20^{\circ} \mathrm{C}$. High temperature intense area are shown near to the welding bead and gradually decrease in temperature near to the edge of the plate.

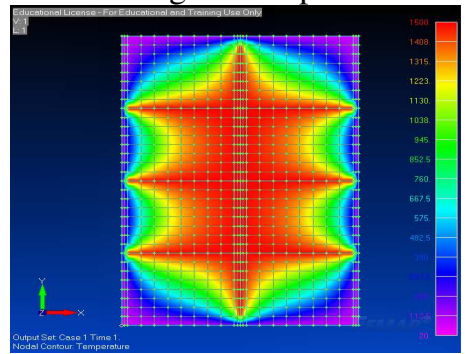

Figure 15. Thermal Analysis of the structure w.r.t. temperature.

\section{Nonlinear Plate Top VonMises Stress Analysis}

(C) Annals of "Dunarea de Jos” University of Galati Fascicle XI- Shipbuilding,2018
The VonMises Stress in this case study is $235 \mathrm{MPa}$. Due to residual stress in the structure cause deformation. Deformation is analysed by the displacement analysis, in the same case study.

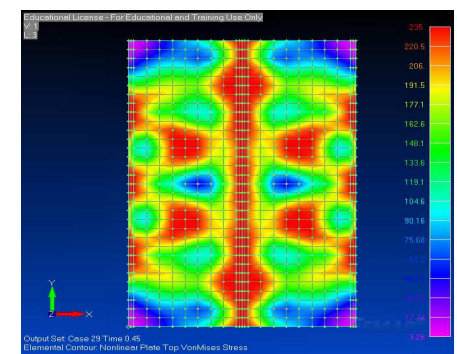

Figure 16. Nonlinear Plate Top VonMises Stress Analysis of the structure.

\section{Displacement Analysis}

Total deformation in this condition is much lower than case study \# 2. Its means that the structure is less deformed. So possibility of distortion is decreased. In this case study the total deformation is $70.41 \mathrm{~mm}$.

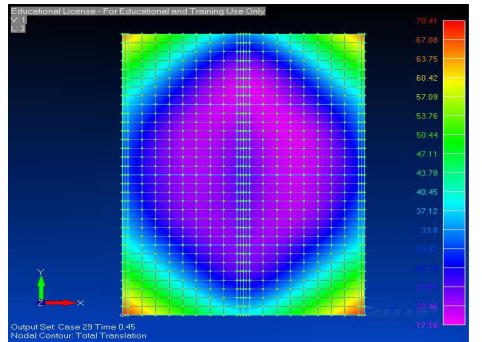

Figure 17. Deformation in the structure.

With mechanical analysis results in this case study shows that the deformation in the structure is lower than the case study \# 2 . 
Case Study \# 5: Comparison between Case Study \# 2 and 4.

Displacement Analysis

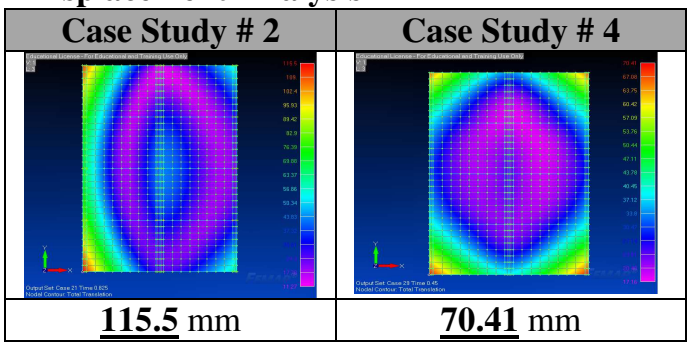

Figure 18. Deformation in the structure.

By comparing both total deformation values, case \# 4 has a smaller value than case \# 2. Its means that the transverse fairing method is applicable in the thin plate of bulkhead structure.

After analysis of fillet joint weld structure through TEP - FEM method give the good agreement of results in Stress and Total translation values. The total deformation value is decreased to $39.03 \%$. Its means that welding distortion is decreased by this transverse fairing method.

\section{CONCLUDING REMARKS}

After computational analysis, the thin plate of the bulkhead shows the good agreement of results to reduce the deformation of the structure by TEP - FEM. Which means that the transverse fairing arrangement of the flat bar can control the deformation in the thin plate. This analysis shows that this solution is highly efficient and accurate to control the welding deformation in the thin plate.

\section{Acknowledgements}

This study has been accomplished in the frame of the EMSHIP - European Masters Course in Advanced Ship and Offshore Design Ref. 159652-1-2009-1-BE-ERA MUNDUS-EMMC, coordinator University of Liege, at Research Centre of the Naval
Architecture Faculty from "Dunarea de Jos" University of Galati.

\section{REFERENCES}

[1]. Jiangchao Wang, Masakazu Shibahara, Xudong Zhang, Hidekazu Murakawa, "Investigation on twisting distortion of thin plate stiffened structure under welding", Journal of Material Processing Technology 212(2012) 1705 - 1715, 2012.

[2]. T. Kumose, T. Yoshida, T. Abbe, O. H, "Predicting of angular distortion caused by one-pass fillet welding", Welding Journal (vol. I) 945 - 56, 1954.

[3]. D. Finch, F. Burdekin, "Effect of welding residual stresses on significance of defects in various types of welded joints", Engineering Fracture mechanics (vol. 5, no. 41) 721 - 35, 1992.

[4]. J. Arnold, R. FD, P. Goff, "Predicting residual stresses in multi-pass weldments with finite element methods", Coompt Structure, (vol. 2, no. 32) $365-78,1989$.

[5]. M. a. DeBiccari, "Prediction of welding distortion”, Welding Journal (vol. I) 172 81, 1997.

[6]. Mehdi Ghanadi, "Managing distortion in welded structures using FEM", Master Thesis, 2013.

[7]. I. B. Z. Barsoum, "Residual stress effects on fatigue life of welded structures using FEM", Engineering failure analysis (no. 16) 449 467, 2009.

[8]. www.shanghaimetal.com/shipbuilding_plate129.htm

[9]. IACS Rule \# 47.

[10]. Dean Deng, Hidekazu Murakawa, Masakazu Shibahara, "Investigations on welding distortion in an asymmetrical curved block by means of numerical simulation technology and experimental method", Computational Material Science 48, 187 - 194, 2010.

[11].Hassan Muneel Syed, "Modeling of residual stresses and distortion due to welding in fillet welds", Master Thesis, 2013.

Paper received on December $31^{\text {th }}, 2018$ 